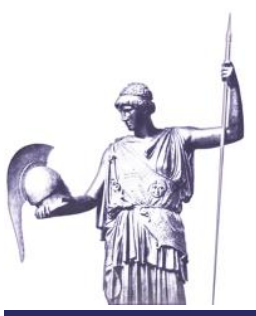

Editorial
Connections: The Quarterly Journal

ISSN 1812-1098, e-ISSN 1812-2973

A. Alymbaeva \& Ph. Fluri, Connections QJ 20, no. 1 (2021): 5-7

https://doi.org/10.11610/Connections.20.1.00

\title{
Lessons from the Post-Totalitarian Transformation of Intelligence Services
}

\section{Aida Alymbaeva and Philipp H. Fluri}

The reform of intelligence and state security services in the 'new' democracies that emerged since the end of the Cold War has remained under-documented and under-analyzed for a long time. This is especially true for smaller countries. Whereas this fact certainly can be explained with the sensitive nature of the business, the lack of data resulted in important lacunae for understanding these services, and obviously also for lessons to be drawn from the transformation processes. This special issue of Connections intends to fill some of the gaps. The editors are delighted to present studies on transformation processes in the structures, legislation, management, and oversight of intelligence and state security services in Hungary, Indonesia, Poland, the South African Republic, and Ukraine. ${ }^{1}$

Various contributors felt encouraged to share data and analysis on ongoing processes of intelligence reform and the evolution of surveillance. Whereas the security of states and alliances remains the main challenge for the established services in democratic states, surveillance technologies have been developed and deployed for business and private use. The dimensions and importance of such commercial surveillance programs do not seem to be sufficiently understood, and therefore remain unrestrained by national legislation and governmental oversight. This collection also presents forward-looking analysis on possible consequences and governance challenges of pandemic surveillance and "surveillance capitalism."

1 Three early contributions, respectively on the post-Cold war intelligenece reforms in the Czech Republic, the Slovak Republic, and Latvia, were published in the SummerFall 2019 edition of Connections: The Quarterly Journal, https://doi.org/10.11610/Con nections.18.3-4. 
Authors offer their views on lessons to be learned in transforming and reforming intelligence services in their respective countries. One of the common features they underline is the delegation of police functions to intelligence services, leading to overlapping mandates with other security agencies. This situation is typical for the post-communist countries (e.g., Poland and Ukraine), where mandated tasks of intelligence agencies have included investigation and pre-trial functions. Authors draw attention to the fact that multi-tasking is heavily influenced by the lingering Soviet legacy when these countries failed to fully overcome it. The cases in this issue show intelligence sector transformations as results of traumatic catalysts rather than gradual evolution. Authors recommend acting decisively and rapidly in such cases. They also argue that unless there is a specific necessity, the reform of the sector is not going to happen quickly.

Weak civilian control is pervasive in the area discussed, along with poor parliamentary control and a dearth of citizens' watchdogs. In addition, limited or non-existent judicial oversight of intelligence agencies is regarded by contributors as a significant shortcoming. They underline that accountability and effectiveness of intelligence services remain limited, as is the public trust. While national legislation on civilian oversight is nominally in place, civilian control is hampered by the dominance of presidents over legislatures and the politicization of the intelligence sector (e.g., the articles on Indonesia and Ukraine), the inadequate capacity of parliamentarians and parliamentary staffers, and insufficient pressure from civil society. In addition, judicial control is only vaguely articulated in national regulatory frameworks.

Another challenge outlined by the authors is the disproportionate use of intelligence and surveillance methods by governments to combat the global COVID-19 pandemic. The powers of intelligence services have been extended for mass surveillance in many countries. Yet, as the authors note, the weakness of civilian control could induce the services to continue using this extended power in the post-Covid situation. This may seriously infringe on the privacy rights of citizens, as proponed in some papers. Moreover, contributors alarm that regulatory activities of many countries, including the EU, in the realm of Artificial Intelligence do not match the pace of development of these technologies. Authors call for immediate actions of governments in this domain.

As a whole, this issue represents a collection of papers featuring these and other setbacks of intelligence sector transformation in different countries and regions. Progress of reforming intelligence services is also highlighted.

The editors are convinced that this special issue will help to fill important gaps in the discussion of intelligence services transformation and oversight. 


\section{Disclaimer}

The views expressed are solely those of the authors and do not represent official views of the PfP Consortium of Defense Academies and Security Studies Institutes, participating organizations, or the Consortium's editors.

\section{Acknowledgment}

Connections: The Quarterly Journal, Vol. 20, 2021, is supported by the United States government.

\section{About the Authors}

Aida Alymbaeva is Director of the Center for Social Innovation and Development in Bishkek, Kyrgyzstan, and Lecturer at the International University of Central Asia. Aida is an experienced researcher and consultant with a demonstrated history of working in the management consulting industry. Skilled in research, policy analysis, and project management, she holds a Master of Science degree in Public Policy Analysis from the Rochester Institute of Technology.

E-mail: aidarochester@gmail.com

Dr. Philipp H. Fluri was a co-founder and long-time deputy director of the Geneva Centre for Security Sector Governance (DCAF; earlier Geneva Centre for the Democratic Control of Armed Forces) and the founder and executive director of DCAF Brussels. He was subsequently an Executive-in-Residence at the Geneva Centre of Security Policy and the Sergio de Mello Chair at the Seton Hall University School of Diplomacy and International Relations. He is currently a professor in the Department of International Affairs at the Wenzao Ursuline University (WZU) in Kaohsiung, Taiwan.

E-mail: drphilippfluri@gmail.com 